\title{
Correction to: Molecular characterization of Ecuadorian quinoa (Chenopodium quinoa Willd.) diversity: implications for conservation and breeding
}

\author{
Juan Salazar • Viviana Jaramillo Roman • Bernardo Gutierrez • \\ Eibertus Nicolaas van Loo $\cdot$ María de Lourdes Torres · Andrés Francisco Torres
}

Published online: 25 November 2019

(C) The Author(s) 2019

\section{Correction to: Euphytica (2019) 215:60 \\ https://doi.org/10.1007/s10681-019-2371-z}

Due to an unfortunate error of miscommunication, two of the co-authors of this manuscript were omitted from the original publication. The correct representation of the authors and their affiliations are listed here and should be treated as definitive.

Juan Salazar ${ }^{1}$, Viviana Jaramillo Roman ${ }^{2}$, Bernardo Gutierrez ${ }^{1,3}$, Eibertus Nicolaas van Loo $^{2}$, María de Lourdes Torres ${ }^{1}$, Andrés Francisco Torres ${ }^{1,2}$

The original article can be found online at https:// doi.org/10.1007/s10681-019-2371-z.

J. Salazar · B. Gutierrez · M. de Lourdes Torres · A. F. Torres $(\square)$

Laboratorio de Biotecnología Vegetal, Colegio de Ciencias Biológicas y Ambientales, Universidad San Francisco de Quito USFQ, Diego de Robles y Vía Interoceánica, Cumbayá, Ecuador

e-mail: andres.torres@wur.nl

V. J. Roman - E. N. van Loo - A. F. Torres

Wageningen UR Plant Breeding, Wageningen University and Research, PO Box 386, 6700 AJ Wageningen, The

Netherlands

B. Gutierrez

Department of Zoology, University of Oxford, 11a

Mansfield Road, Oxford OX1 3SZ, UK
1. Laboratorio de Biotecnología Vegetal, Colegio de Ciencias Biológicas y Ambientales, Universidad San Francisco de Quito USFQ, Diego de Robles y Vía Interoceánica, Cumbayá, Ecuador

2. Wageningen UR Plant Breeding, Wageningen University and Research, PO Box 386, 6700 AJ Wageningen, The Netherlands

3. Department of Zoology, University of Oxford, 11a Mansfield Road, Oxford OX1 3SZ, UK

Furthermore, the acknowledgments section has been adapted to match the changes in authorship. The corrected acknowledgements, presented below, are definitive:

This research was funded with a Chancellor's Grant (2015) from Universidad San Francisco de Quito USFQ (Quito-Ecuador). Germplasm access and research permit were granted by the Ministry of Environment of Ecuador (MAE-DNB-CM-20160044). The authors would like to acknowledge the technical assistance offered by researchers at the Plant Biotechnology Laboratory (COCIBA, USFQ), as well as Dr. Leonardo Zurita for his assistance with georeferenced mapping. The authors would also like to acknowledge Dr. Gerard van der Linden (Wageningen University and Research) for supporting our efforts to search and collect quinoa germplasm throughout the Andes of Ecuador.

Open Access This article is distributed under the terms of the Creative Commons Attribution 4.0 International License (http:// creativecommons.org/licenses/by/4.0/), which permits 
unrestricted use, distribution, and reproduction in any medium, provided you give appropriate credit to the original author(s) and the source, provide a link to the Creative Commons license, and indicate if changes were made.
Publisher's Note Springer Nature remains neutral with regard to jurisdictional claims in published maps and institutional affiliations. 